\title{
Successful recovery of COVID-19-associated recurrent diarrhea and gastrointestinal hemorrhage using convalescent plasma
}

\author{
Li-Bo Zhang ${ }^{1,2+}{ }^{+}$, Rong-Rong Pang ${ }^{1,2+}$, Qing-Hua Qiao ${ }^{3,4+}$, Zhi-Hua Wang ${ }^{4,5,6+}$, Xin-Yi Xia ${ }^{1,4,6^{*}}$ D, \\ Chang-Jun Wang ${ }^{6,7^{*}}$ and XiaO-Li Xu,
}

\begin{abstract}
Background: Gastrointestinal symptoms are not rare among coronavirus disease 2019 (COVID-19) patients, but there have been no reports regarding convalescent plasma therapy for the recovery of gastrointestinal problems in COVID-19 patients.

Case presentation: We present two cases of patients with COVID-19-associated recurrent diarrhea and positive fecal occult blood who successfully recovered after a one-time convalescent plasma administration.

Conclusion: When COVID-19 patients develop recurrent or refractory gastrointestinal symptoms and fail to respond to the available treatment, alternative therapy with convalescent plasma administration may be considered.
\end{abstract}

Keywords: Coronavirus disease 2019 (COVID-19), Convalescent plasma, SARS-CoV-2 virus, Gastrointestinal symptoms

\section{Background}

Coronavirus disease 2019 (COVID-19) is an emerging disease caused by a novel severe acute respiratory syndrome coronavirus 2 (SARS-CoV-2), and it has spread throughout the world [1]. In terms of clinical presentation of the new coronavirus infection, the main clinical presentation is acute febrile illness with pulmonary manifestations [2]. However, recent studies have reported the detection of the SARS-CoV-2 virus in feces [3-5], and endoscopic examination revealed COVID-19associated ulcers and bleeding in gastrointestinal tissues in some patients [6]. In autopsy studies, the beaded

\footnotetext{
* Correspondence: xinyixia@nju.edu.cn; science2008@hotmail.com; xx12019kt@sina.com

'Li-Bo Zhang, Rong-Rong Pang, Qing-Hua Qiao and Zhi-Hua Wang contributed equally to this work.

'COVID-19 Research Center, Institute of Laboratory Medicine, Jinling Hospital, Nanjing University School of Medicine, the First School of Clinical Medicine, Southern Medical University, Nanjing 210002, Jiangsu, China

${ }^{6}$ Joint Expert Group for COVID-19, Wuhan Huoshenshan Hospital, Wuhan 430100, Hubei, China

Full list of author information is available at the end of the article
}

intestine may be a more intuitive finding [7]. Accumulated evidence supports SARS-CoV-2 being transmitted through the gastrointestinal tract and targeting the gastrointestinal tract through angiotensin-converting enzyme 2 (ACE2) [8].

In fact, gastrointestinal symptoms are not rare in COVID-19 patients. In previous reports, $2-10 \%$ of patients with COVID-19 had gastrointestinal symptoms, such as diarrhea, vomiting and nausea [9-13]. Gastrointestinal bleeding was also found in SARS-CoV-2 infected patients [6, 14].

To date, there is no effective antiviral therapy for COVID-19. The main treatments are supportive care in the forms of supplementary oxygen therapy and extracorporeal membrane oxygenation. Convalescent plasma (CP) has been used as a last resort to treat many infectious diseases. Expectedly, $\mathrm{CP}$ infusion was suggested for the treatment of SARS-CoV-2 infection, and it was actually tried in several cases during the COVID-19 outbreak. Ye et al. showed a significant elimination of the 
virus and resolution of lung infiltrates in patients treated with CP [15]. Zhang et al. reported a severe COVID-19 patient who had an improvement in her clinical status after CP infusion in Nanjing [16]. Nevertheless, there have been no reports regarding convalescent plasma therapy for the recovery of gastrointestinal problems in COVID-19 patients. Therefore, we present two cases of patients with COVID-19-associated recurrent diarrhea and positive fecal occult blood who successfully recovered after a one-time convalescent plasma administration.

\section{Case presentation}

\section{Case 1}

A previously healthy 69-year-old woman was admitted to Wuhan Huoshenshan Hospital with a 20-day history of anorexia and fatigue, as well as a 7-day history of fever. Her highest temperature was $38.5^{\circ} \mathrm{C}$, accompanied by progressing fatigue and anorexia after exposure at a bank in Wuhan 1 month prior. After that, she was admitted to a local hospital and was administered a medical history of Lianhuaqingwen capsule and arbidol, with a subsequent improvement of her respiratory symptoms.
On admission, her temperature had returned to normal and the SARS-CoV-2 test of her throat swab was negative. In contrast, she presented with nausea, anorexia and loose stool, with an intermittent dry cough during the preceding 3 weeks. A routine stool check demonstrated a loose sample with positive occult blood. Routine blood, chemistry and coagulation tests showed no abnormalities. The pertinent laboratory results are summarized in Table 1 . The lymphocyte subset percentages are summarized in Table 2.

The initial treatment was supportive and most of her symptoms improved, including cough and shortness of breath; however, after an 18-day hospitalization, she presented recurrent gastrointestinal complaints of anorexia and mild diarrhea. On hospital day (HD) 21, HD25 and HD29, the SARS-CoV-2 RNA tests of her throat swabs were positive, after two consecutively negative results on HD16 and HD19.

On HD30, approximately $400 \mathrm{~mL}$ of CP was administered to the patient. No adverse reaction occurred after $\mathrm{CP}$ infusion. On HD31, SARS-CoV-2 RNA tests were negative on her throat and anal swabs, whereas SARSCoV-2 RNA remained detectable in her nasal swab. On

Table 1 Serial laboratory results of the patients

\begin{tabular}{|c|c|c|c|c|c|c|c|c|c|c|}
\hline \multirow[t]{2}{*}{ Variables } & \multicolumn{5}{|c|}{ Case 1} & \multicolumn{5}{|c|}{ Case 2} \\
\hline & HD2 & HD8 & HD30 & HD32 & HD33 & HD2 & HD9 & HD12 & HD14 & HD17 \\
\hline White blood cell count $\left(\times 10^{9} / \mathrm{L}\right)$ & 3.4 & 4.2 & 6.6 & 6 & - & 13.8 & 7.4 & 6.9 & 7.8 & 11.5 \\
\hline Neutrophils (\%) & 59 & 53.9 & 62.2 & 54.9 & - & 90 & 81.8 & 81 & 83.1 & 86.3 \\
\hline Lymphocytes (\%) & 30 & 37.2 & 25.8 & 34.2 & - & 5.4 & 10.4 & 10.9 & 9.5 & 8.5 \\
\hline Hemoglobin (g/L) & 130 & 138 & 132 & 142 & - & 87 & 84 & 89 & 91 & 96 \\
\hline Platelet count $\left(\times 10^{9} / \mathrm{L}\right)$ & 165 & 179 & 197 & 181 & - & 188 & 235 & 222 & 195 & 245 \\
\hline C-reactive protein (mg/L) & 0.34 & 0.51 & 1.22 & 1.11 & - & 42.4 & 15.1 & 9.59 & 4.81 & 1.99 \\
\hline Interleukin-6 (pg/mL) & - & - & - & 3.62 & - & 43.6 & - & - & - & - \\
\hline Procalcitonin (ng/mL) & - & - & - & - & 0.07 & 0.24 & 0.03 & - & - & - \\
\hline Albumin $(\mathrm{g} / \mathrm{L})$ & 39.5 & 39 & - & - & 38.7 & 30.5 & 34.2 & 40.3 & 39 & 41.6 \\
\hline Alanine aminotransferase (IU/L) & 16.7 & 13.4 & - & - & 11 & 8.3 & 15.7 & 12.2 & 9.6 & 7.9 \\
\hline Aspartate aminotransferase (IU/L) & 31 & 29.3 & - & - & 23.8 & 11.6 & 8.9 & 8.7 & 8 & 7.2 \\
\hline Lactate dehydrogenase (IU/L) & 201 & 180 & - & - & 192 & 243 & 187 & - & 163 & 186 \\
\hline a-hydroxybutyrate dehydrogenase (IU/L) & 166 & 144 & - & - & 151 & 201 & 160 & - & 141 & 157 \\
\hline Creatine kinase (IU/L) & 51.2 & 49.9 & - & - & 38 & 12.7 & 6.6 & - & 6.2 & 7.4 \\
\hline Cardiac troponin I (ng/mL) & 0.01 & 0.01 & - & - & - & - & - & - & - & - \\
\hline Urea (mmol/L) & 1.69 & 2.95 & - & - & 4.76 & 2.03 & 2.34 & - & 3.17 & 3.3 \\
\hline Creatinine $(\mu \mathrm{mol} / \mathrm{L})$ & 60.9 & 55.2 & - & - & 53.2 & 59.5 & 39.3 & - & 38.6 & 39.5 \\
\hline Cys-C (mg/L) & 0.95 & 1.01 & - & - & 0.99 & 1.18 & 1.01 & - & 1.13 & 1.23 \\
\hline Prothrombin time (s) & 13 & 12.9 & - & 12.8 & - & 12.2 & 12.6 & - & 12.8 & 12.7 \\
\hline Activated partial-thromboplastin time (s) & 29.3 & 27.6 & - & 28.6 & - & 29 & 24.5 & - & 26.5 & 23.6 \\
\hline Fibrinogen ( $g / L)$ & 2.59 & 2.93 & - & 2.8 & - & 3.63 & 3.69 & - & 2.95 & 2.96 \\
\hline D-dimer (mg/L) & 0.13 & 0.08 & - & 0.25 & - & 1.05 & 1.15 & - & 0.66 & 1.04 \\
\hline
\end{tabular}

-. No data; HD Hospital day 
Table 2 Lymphocyte subset percentages of both patients before CP infusion (on HD8 for case 1; HD7 for case 2)

\begin{tabular}{lllllll}
\hline Patient & CD3+ (\%) & CD3 + CD4+ (\%) & CD3 + CD8+ (\%) & CD4/CD8 ratio & CD3-CD19+ (\%) & CD3-(CD16+/CD56+) (\%) \\
\hline Case 1 & 78.40 & 55.20 & 22.10 & 2.5 & 7.00 & 14.40 \\
Case 2 & 59.60 & 27.20 & 25.30 & 1.1 & 26.40 & 8.50
\end{tabular}

$C P$ Convalescent plasma, HD Hospital day

HD33, the patient's condition was much improved, with subsiding anorexia and nausea. On HD35, the SARSCoV-2 RNA test of her nasal swab returned negative, which was consistent with her throat swab. On HD36, the patient recovered from both respiratory and gastrointestinal symptoms except for mild diarrhea. She showed complete recovery on HD38 and was discharged on HD39 (Fig. 1). SARS-CoV-2 RNA remained negative at her follow-up visits on quarantine day (QD) 6 and QD10.

\section{Case 2}

A 50-year-old woman with a history of systemic lupus erythematosus (SLE), lacunar infarction (LI), and diabetes presented with intermittent fever, headache, dizziness and shortness of breath for 7 days. Her highest temperature was $38^{\circ} \mathrm{C}$, and she experienced chills 1 month prior. She was later treated for COVID-19 on the basis of characteristic computed tomography (CT) imaging of the thorax at another hospital in Wuhan. She received prednisone $30 \mathrm{mg}$ once daily with ciclosporin, hydroxychloroquine, and total glucosides of paeony for the treatment of SLE.

At the time of arrival, the patient had recovered from dyspnea, and she maintained a normal temperature throughout the hospitalization. On examination, she was negative for the SARS-CoV-2 nucleic acid test,

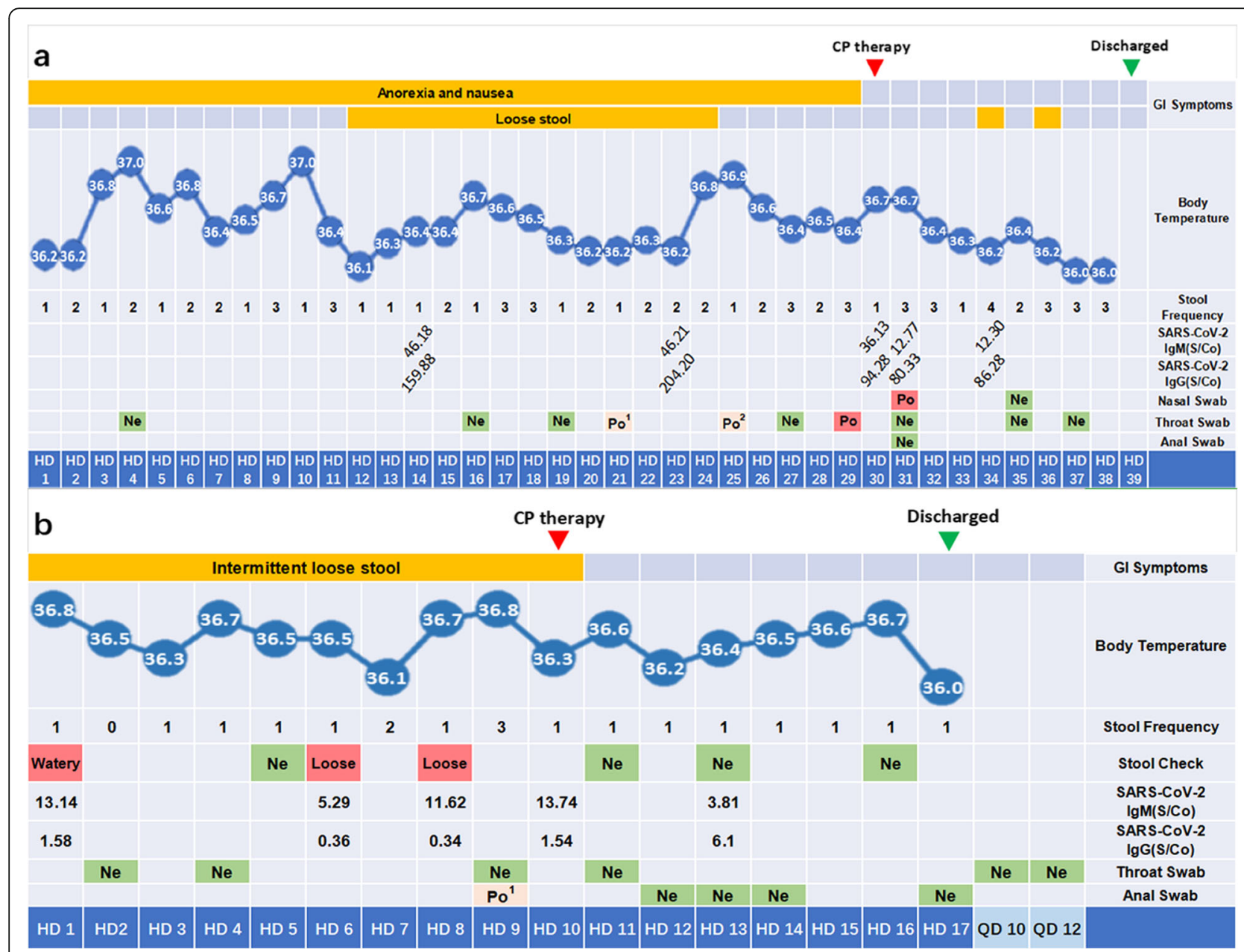

Fig. 1 Clinical course and laboratory findings of the patients. a. Clinical course and laboratory findings of the patient in Case 1; b. Clinical course and laboratory findings of the patient in Case 2; Ne. Denotes negative; Po ${ }^{1}$. Positive for the nucleoprotein (N) gene region target; Po ${ }^{2}$. Positive for the open reading frame (ORF) target; Po. Positive for the two aforementioned targets 
accompanied by a positive IgM serology finding. A routine stool check revealed a watery stool sample. Serial fecal examinations from HD1 to HD10 revealed an intermittent course of diarrhea, and she had positive fecal occult blood on HD5. A positive result of a SARSCoV-2 RNA test from an anal swab provided the evidence of gastrointestinal infection on HD9. Additionally, a routine blood examination demonstrated a low percentage of lymphocytes (5.4\%) but relatively normal levels of the most abundant subpopulations (Table 2), a low concentration of hemoglobin $(87 \mathrm{~g} / \mathrm{L})$ and elevated C-reactive protein (CRP) $(42.4 \mathrm{mg} / \mathrm{L})$. Further laboratory details are summarized in Table 1.

As she had a persistent low level of anti-SARS-CoV-2 IgG antibodies, which might be due to the administration of immunosuppressors such as prednisone and ciclosporin for SLE therapy, CP transfusion was considered. On HD10, $200 \mathrm{~mL}$ of ABO-compatible CP with relative high titers of anti-SARS-CoV-2 antibodies (Table 3) was transfused to the patient. The stool consistency was improved immediately after $\mathrm{CP}$ infusion, while the fecal occult blood test turned to negative on HD13, but later turned to weak positive again on HD16. Two days after the CP infusion, serial tests from anal swabs of SARS-CoV-2 RNA were consecutively negative on HD12, HD13, HD14 and HD17, and CRP decreased to the normal range $(1.99 \mathrm{mg} / \mathrm{L})$. She showed complete recovery and was discharged on HD17, and SARS-CoV2 RNA remained negative on QD10 and QD12 (Fig. 1).

\section{Discussion and conclusions}

Gastrointestinal symptoms such as diarrhea and anorexia have been widely reported in COVID-19 patients. However, this is the first report focused on the therapeutic effect of CP on COVID-19-associated gastrointestinal symptoms.

A previous study reported that COVID-19 patients with gastrointestinal symptoms were more often to have an illness duration of more than 7 days compared with those without symptoms [17]. Consistent with this finding, our patients experienced long hospital stays (39 days for Case 1 and 17 days for Case 2). A recent study revealed that all patients were tested positive for antiSARS-CoV-2 IgG within 19 days after the symptom onset of COVID-19, and during the first 3 weeks after symptom onset, IgG and IgM antibody titers were increased [18]. From symptom onset to CP infusion, both patients exceeded the timing by a large margin (62 days for Case 1 and 42 days for Case 2). Both patients presented afebrile and were negative for SARS-CoV-2 in a throat swab test on admission, while gastrointestinal symptoms and positive anal swabs provided evidence of gastrointestinal infection. The levels of IgG antibodies, typically the antibody against surface spike protein receptor binding domain (RBD), which is an indication of neutralizing activity [19], were relatively high in both $\mathrm{CP}$ units. After $\mathrm{CP}$ infusion, the levels of antibodies against all SARS-CoV-2 subunits were elevated in one patient but were declined in the other patient (Table 3). However, fortunately, both patients recovered from their gastrointestinal symptoms and were discharged from the hospital.

The symptom of diarrhea can be aggravated by various drugs, including antibiotics, antiviral agents and certain traditional Chinese medicines, which usually cause nausea and diarrhea. Similarly, gastrointestinal hemorrhage can also be affected by many factors, such as the administration of corticosteroids and nonsteroidal antiinflammatory drugs (NSAIDs) or the development of ulcer after physiological stress. It is difficult to assess whether the gastrointestinal manifestations were primary or secondary to SARS-CoV-2 infection. Although we selected two cases with coexisting symptoms of diarrhea and gastrointestinal bleeding and considered that the symptoms were more likely a result of SARS-CoV-2, it was still challenging to trace whether the gastrointestinal

Table 3 Levels of antibodies against subunits of SARS-CoV-2 from donors of CP and recipients after CP infusion

\begin{tabular}{|c|c|c|c|c|c|c|c|c|}
\hline \multirow[t]{2}{*}{ Antibodies } & \multicolumn{2}{|c|}{ Case 1 Donor } & \multicolumn{2}{|c|}{ Case 1 Recipient } & \multicolumn{2}{|c|}{ Case 2 Donor } & \multicolumn{2}{|c|}{ Case 2 Recipient } \\
\hline & $\mathrm{FI}$ & S/Co & FI & S/Co & $\mathrm{FI}$ & S/Co & $\mathrm{FI}$ & S/Co \\
\hline \multicolumn{9}{|l|}{$\lg M$} \\
\hline S-IgM & 480,724 & 3.251 & 820,248 & 5.547 & 977,929 & 6.614 & 71,465 & 0.483 \\
\hline RBD-lgM & 523,293 & 1.951 & $1,825,435$ & 6.805 & $1,114,862$ & 4.156 & 349,693 & 1.304 \\
\hline $\mathrm{N}-\lg \mathrm{M}$ & 295,140 & 1.740 & 105,401 & 0.621 & 844,852 & 4.981 & 222,735 & 1.313 \\
\hline \multicolumn{9}{|l|}{$\lg G$} \\
\hline S-lgG & $1,338,844$ & 10.949 & $4,699,322$ & 38.430 & $2,106,545$ & 17.227 & 21,736 & 0.178 \\
\hline RBD-lgG & $3,121,978$ & 15.601 & $9,852,641$ & 49.235 & $2,075,661$ & 10.372 & 8946 & 0.045 \\
\hline$N-\lg G$ & $1,650,382$ & 8.038 & $8,326,749$ & 40.553 & $3,731,186$ & 18.171 & 19,841 & 0.097 \\
\hline
\end{tabular}

CP Convalescent plasma, FI Fluorescent intensity, S/Co Signal to cut-off ratio, IgM Immunoglobulin M, S-IgM S protein specific immunoglobulin M, RBD-IgM Immunoglobulin $M$ against surface spike protein receptor binding domain, $N$-lgM N protein specific immunoglobulin $M$, IgG Immunoglobulin $\mathrm{G}$, $S$-lgG $\mathrm{S}$ protein specific immunoglobulin $\mathrm{G}, R B D$-IgG Immunoglobulin $\mathrm{G}$ against surface spike protein receptor binding domain, $N$-IgG $\mathrm{N}$ protein specific immunoglobulin $\mathrm{G}$ 
abnormalities were due to SARS-CoV-2 or other factors, such as arbidol in Case 1 and prednisone administration in Case 2, which might confound the results.

Due to limitations imposed by insufficient knowledge of the virus at the beginning of the epidemic and an unprecedented demand in medical resources caused by the sudden outbreak, more data such as the presence of SARS-CoV-2 RNA in the stool is needed to strengthen our findings. However, with the increasingly improved understanding of COVID-19, a stool test or anal swab test should be taken into consideration. A previous study demonstrated that a time window might exist between respiratory and fecal specimens of PCR tests, which indicates that the virus might survive longer in the gastrointestinal tract than in the respiratory tract [20]. More formidably, in another study, Hosoda et al. reported that even after recovering from diarrhea due to COVID-19, patients could continue to excrete the virus for weeks [21]. Therefore, we suggest that a further negative nucleic acid result on an anal swab or feces test is needed before a patient is discharged from the hospital, rather than the absence of gastrointestinal symptoms. In some cases, COVID-19 patients may also present with atypical symptoms such as acute abdomen [22, 23], and it remains unclear whether COVID-19 could spread via the fecal-oral route. Given these risks, we recommend routine detection of SARS-CoV-2 for patients with a newonset digestive symptom after a possible COVID-19 exposure.

In conclusion, we reported two cases of patients with COVID-19-associated recurrent diarrhea and positive fecal occult blood who successfully recovered after a one-time convalescent plasma administration, and we called attention to gastrointestinal infection due to COVID-19. When COVID-19 patients develop recurrent or refractory gastrointestinal symptoms and fail to respond to the available treatment, alternative therapy with convalescent plasma may be considered.

\section{Abbreviations \\ ACE2: Angiotensin-converting enzyme 2; COVID-19: Coronavirus disease 2019; CP: Convalescent plasma; CRP: C-reactive protein; CT: Computed tomography; HD: Hospital day; LI: Lacunar infarction; ORF: Open reading frame; QD: Quarantine day; RBD: Receptor binding domain; SLE: Systemic lupus erythematosus}

\section{Acknowledgements}

We gratefully acknowledge the intense individual effort and support from many sources to make this study possible, as well as the contributions of plasma donors.

\section{Authors' contributions}

$X Y X, C J W$ and $X L X$ have full access to all the data in the study and take responsibility for the integrity of the data and the accuracy of the data analysis. XYX, XLX, and CJW conducted concept and design. QHQ, ZHW and LBZ performed the data collection, analysis and interpretation. RRP drafted the manuscript. All authors read and approved the final manuscript.

\section{Funding}

This work was supported by the Key Foundation of Wuhan Huoshenshan Hospital (2020 [18]), Key Research \& Development Program of Jiangsu Province (BE2018713), Medical Innovation Project of Logistics Service (18JS005), the Foundation of Jiangsu Population Association (JSPA2019017), and Medical Science and Technology Development Foundation, Nanjing Department of Health (YKK18179).

\section{Availability of data and materials}

Not applicable.

\section{Ethics approval and consent to participate}

This study was approved by the Medical Ethical Committee of Wuhan Huoshenshan Hospital with the participants' written informed consent (HSSL L011).

\section{Consent for publication}

Not applicable.

\section{Competing interests}

The authors declare that they have no competing interests.

\section{Author details}

${ }^{1}$ COVID-19 Research Center, Institute of Laboratory Medicine, Jinling Hospital, Nanjing University School of Medicine, the First School of Clinical Medicine, Southern Medical University, Nanjing 210002, Jiangsu, China. ${ }^{2}$ Department of Laboratory Medicine, Nanjing Red Cross Blood Center, Nanjing 210003, Jiangsu, China. ${ }^{3}$ Medical and Technical Support Department, Pingdingshan Medical District, the 989th Hospital, Pingdingshan 467000, Henan, China. ${ }^{4}$ Department of Laboratory Medicine \& Blood Transfusion, Wuhan Huoshenshan Hospital, Wuhan 430100, Hubei, China. ${ }^{5}$ Department of Laboratory Medicine \& Blood Transfusion, the 907th Hospital, Nanping

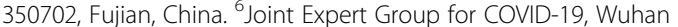
Huoshenshan Hospital, Wuhan 430100, Hubei, China. ${ }^{7}$ Center for Disease Control and Prevention of PLA, No. 20 Dongda Street, Fengtai District, Beijing 100071, China. ${ }^{8}$ Department of Medical Administration, Jinling Hospital, Nanjing University School of Medicine, No. 305 East Zhongshan Road, Nanjing 210002, Jiangsu, China.

Received: 18 May 2020 Accepted: 14 September 2020

Published online: 23 September 2020

\section{References}

1. Bedford J, Enria D, Giesecke J, Heymann DL, Ihekweazu C, Kobinger G, et al. COVID-19: towards controlling of a pandemic. Lancet. 2020;395(10229): 1015-8.

2. Baj J, Karakula-Juchnowicz H, Teresinski G, Buszewicz G, Ciesielka M, Sitarz E, et al. COVID-19: specific and non-specific clinical manifestations and symptoms: the current state of knowledge. J Clin Med. 2020;9(6):1753. https://doi.org/10.3390/jcm9061753.

3. Chen $Y$, Chen L, Deng Q, Zhang G, Wu K, Ni L, et al. The presence of SARSCoV-2 RNA in the feces of COVID-19 patients. J Med Virol. 2020;92(7):833-40.

4. Wang W, Xu Y, Gao R, Lu R, Han K, Wu G, et al. Detection of SARS-CoV-2 in different types of clinical specimens. JAMA. 2020;323(18):1843-4.

5. Zhang T, Cui X, Zhao X, Wang J, Zheng J, Zheng G, et al. Detectable SARSCoV-2 viral RNA in feces of three children during recovery period of COVID19 pneumonia. J Med Virol. 2020;92(7):909-14. https://doi.org/10.1002/jmv. 25795.

6. Lin L, Jiang X, Zhang Z, Huang S, Zhang Z, Fang Z, et al. Gastrointestinal symptoms of 95 cases with SARS-CoV-2 infection. Gut. 2020;69(6):997-1001.

7. Liu Q, Wang RS, Qu GQ, Wang YY, Liu P, Zhu YZ, et al. Gross examination report of a COVID-19 death autopsy. Fa Yi Xue Za Zhi. 2020;36(1):21-3. https://doi.org/10.12116/j.issn.1004-5619.2020.01.005.

8. Zhang H, Li HB, Lyu JR, Lei XM, Li W, Wu G, et al. Specific ACE2 expression in small intestinal enterocytes may cause gastrointestinal symptoms and injury after 2019-nCoV infection. Int J Infect Dis. 2020;96:19-24. https://doi. org/10.1016/j.ijid.2020.04.027.

9. Chen N, Zhou M, Dong X, Qu J, Gong F, Han Y, et al. Epidemiological and clinical characteristics of 99 cases of 2019 novel coronavirus pneumonia in Wuhan, China: a descriptive study. Lancet. 2020;395(10223):507-13. 
10. Guan WJ, Ni ZY, Hu Y, Liang WH, Ou CQ, He JX, et al. Clinical characteristics of coronavirus disease 2019 in China. N Engl J Med. 2020;382(18):1708-20.

11. Huang C, Wang Y, Li X, Ren L, Zhao J, Hu Y, et al. Clinical features of patients infected with 2019 novel coronavirus in Wuhan, China. Lancet. 2020;395(10223):497-506

12. Wang D, Hu B, Hu C, Zhu F, Liu X, Zhang J, et al. Clinical characteristics of 138 hospitalized patients with 2019 novel coronavirus-infected pneumonia in Wuhan, China. JAMA. 2020;323(11):1061-9. https://doi.org/10.1001/jama. 2020.1585 .

13. Zhu N, Zhang D, Wang W, Li X, Yang B, Song J, et al. A novel coronavirus from patients with pneumonia in China, 2019. N Engl J Med. 2020;382(8): $727-33$

14. Xiao F, Tang M, Zheng X, Liu Y, Li X, Shan H. Evidence for gastrointestinal infection of SARS-CoV-2. Gastroenterology. 2020;158(6):1831-3.

15. Ye M, Fu D, Ren Y, Wang F, Wang D, Zhang F, et al. Treatment with convalescent plasma for COVID-19 patients in Wuhan, China. J Med Virol. 2020. https://doi.org/10.1002/jmv.25882.

16. Zhang L, Pang R, Xue X, Bao J, Ye S, Dai Y, et al. Anti-SARS-CoV-2 virus antibody levels in convalescent plasma of six donors who have recovered from COVID-19. Aging (Albany NY). 2020;12(8):6536-42.

17. Nobel YR, Phipps M, Zucker J, Lebwohl B, Wang TC, Sobieszczyk ME, et al. Gastrointestinal symptoms and COVID-19: case-control study from the United States. Gastroenterology. 2020;159(1):373-5.

18. Long QX, Liu BZ, Deng HJ, Wu GC, Deng K, Chen YK, et al. Antibody responses to SARS-CoV-2 in patients with COVID-19. Nat Med. 2020;26(6): 845-8.

19. To KK, Tsang OT, Leung WS, Tam AR, Wu TC, Lung DC, et al. Temporal profiles of viral load in posterior oropharyngeal saliva samples and serum antibody responses during infection by SARS-CoV-2: an observational cohort study. Lancet Infect Dis. 2020;20(5):565-74.

20. Tian Y, Rong L, Nian W, He Y. Review article: gastrointestinal features in COVID-19 and the possibility of faecal transmission. Aliment Pharmacol Ther. 2020:51(9):843-51.

21. Hosoda T, Sakamoto M, Shimizu H, Okabe N. SARS-CoV-2 enterocolitis with persisting to excrete the virus for approximately two weeks after recovering from diarrhea: a case report. Infect Control Hosp Epidemiol. 2020;41(6):753-4.

22. Blanco-Colino R, Vilallonga R, Martin R, Petrola C, Armengol M. Suspected acute abdomen as an extrapulmonary manifestation of Covid-19 infection. Cir Esp. 2020;98(5):295-6

23. Tullie L, Ford K, Bisharat M, Watson T, Thakkar H, Mullassery D, et al. Gastrointestinal features in children with COVID-19: an observation of varied presentation in eight children. Lancet Child Adolesc Health. 2020;4(7):e19-20.

Ready to submit your research? Choose BMC and benefit from:

- fast, convenient online submission

- thorough peer review by experienced researchers in your field

- rapid publication on acceptance

- support for research data, including large and complex data types

- gold Open Access which fosters wider collaboration and increased citations

- maximum visibility for your research: over $100 \mathrm{M}$ website views per year

At $\mathrm{BMC}$, research is always in progress.

Learn more biomedcentral.com/submissions 